\title{
Perubahan Sifat Kimia Tanah Vertik KambisolAkibat Pemberian Jenis Pupuk dan Varietas Kacang Tanah (Arachis hypogaea L.) Di Muara Tiga Di Kabupaten Pidie
}

\author{
Changes in Soil Vertical Chemistry of Cambisol Due to the Provision of Peanut Fertilizers \\ and Varieties (Arachis hypogaea L.) in Muara Tiga in DistrictPidie
}

\author{
Wardia Rahmi $^{1}$, Teuku Alvisyahrin ${ }^{* 1}$ dan Zainabun*1 \\ ${ }^{1}$ Mahasiswa Program Studi Agroteknologi, Fakultas Pertanian, Universitas Syiah Kuala \\ ${ }^{*}$ Staf Dosen Program Studi Ilmu Tanah, Fakultas Pertanian, Universitas Syiah Kuala
}

\begin{abstract}
Abstrak. Tujuan penelitin yaitu untuk mengetahui perubahan sifat kimia tanah akibat pemberian jenis pupuk dan penggunaan varietas kacang tanah serta interaksi antara perlakuan jenis pupuk dan varietas kacang tanah pada tanah Vertik Kambisol.. Penelitian ini telah dilaksanakan di Muara Tiga dan di Laboratorium Penelitian Tanah dan Tanaman Fakultas Pertanian Universitas Syiah Kuala. Waktu pelaksanaan dimulai dari bulan juli 2016oktober 2016. Rancangan percobaan yang digunakan dalam penelitian ini adalah Rancangan Acak Kelompok (RAK) pola faktorial $4 \times 5$ dengan 3 ulangan. Adapun faktor yang diteliti yaitu jenis pupuk (j) varietas kacang tanah (V). Peubah yang diamati meliputi $\mathrm{pH} \mathrm{H}_{2} \mathrm{O}$, C-organik, N-total. Hasil penelitian menunjukkan aplikasi jenis pupuk berpengaruh nyata terhadap \% C-organik tanah umur 45 hari setelah tanah (HST) kacang tanah. Hasil penelitian menunjukkan bahwa beberapa jenis pupuk berpengaruh untuk meningkatkan kesuburan tanah Vertik Kambisol. Nilai tertinggi untuk C-organik adalah 1,74\% (pupuk kandang 4,68 $\mathrm{kg} \mathrm{plot}^{-1}+$ NPK 0,117 kg plot ${ }^{-1}+$ kompos 4,68 $\mathrm{kg} \mathrm{plot}^{-1}$ ) pada umur $45 \mathrm{HST}$ kacang tanah. Hasil analisis perlakuan beberapa varietas kacang tanah tidak berpengaruh nyata terhadap pemberian perlakuan jenis pupuk serta tidak terdapat interaksi antara perlakuan jenis pupuk dan varietas kacang tanah terhadap $\mathrm{pH}_{2} \mathrm{O}$, C-organik, $\mathrm{N}$ total, pada tanah Vertik Kambisol.
\end{abstract}

Kata kunci: Tanah Vertik Kambisol, Kacang Tanah, Jenis Pupuk.

HST: Hari Setelah Tanam

\begin{abstract}
Abstrack. The aim of the research was to determine changes in soil chemical properties due to the application of fertilizer types and the use of peanut varieties as well as interactions between fertilizer type treatment and peanut varieties on Vertical Cambisol soil. This research has been carried out in the Laweung area of Pidie Regency and at the Soil and Plant Research Laboratory of the Faculty of Agriculture, Syiah Kuala University. The implementation time starts from July 2016 to October 2016. The experimental design used in this study was a Randomized Block Design (RBD) 4 x 5 factorial pattern with 3 replications. The factors studied were the type of fertilizer $(\mathrm{j})$ variety of peanut $(\mathrm{V})$. The variables observed included $\mathrm{pH} \mathrm{H} 2 \mathrm{O}, \mathrm{C}$-organic, $\mathrm{N}$-total. The results showed that the application of fertilizer types significantly affected\% C soil organic age 45 days after soil (HST) peanuts. The results showed that several types of fertilizers had an effect on increasing Vertical soil fertility of cambisol. The highest value for C-organic is $1.74 \%$ (manure $4.68 \mathrm{~kg}$ plot- $1+$ NPK $0.117 \mathrm{~kg}$ plot- $1+$ compost 4.68 $\mathrm{kg}$ plot-1) at $45 \mathrm{HST}$ of peanut. The results of the treatment analysis of several peanut varieties did not significantly affect the administration of fertilizer type and there was no interaction between the treatment of fertilizer types and peanut varieties on $\mathrm{pH} \mathrm{H} 2 \mathrm{O}$, organic $\mathrm{C}$, total $\mathrm{N}$, on cambisol Vertical soil
\end{abstract}

Keywords: Vertic Cambisol Soil, Peanuts, Type Of Fertilizer

DAP: Days After Planting

\section{PENDAHULUAN}

Kambisol merupakan jenis tanah yang tergolong tanah baru berkembang yang mempunyai potensi untuk pengembangan tanaman pertanian, biasanya mempunyai tekstur yang beragam dari kasar hingga halus,kedalaman efektifnya beragam dari dangkal hingga dalam, di dataran rendah pada umumnya tebal, sedangkan pada daerah-daerah lereng curam solumnya tipis (Tufaila dan Alam, 2014).Produksi pertanian pada lahan kering jauh lebih rendahjika dibandingkan dengan produksi pertanian pada sistem lahan basah, karena lahan 
basah umumnya memiliki tingkat kesuburan tanah yang relatif lebih tinggi sedangkan lahan kering memiliki kadar bahan organik rendah (Abdurachmanet al., 2008).

Tanah Kambisol merupakan salah satu jenis tanah mineral yang mempunyai ciri: $\mathrm{pH}$ agak masam,ketersediaan $\mathrm{Ca}, \mathrm{Mg}, \mathrm{Na}, \mathrm{N}, \mathrm{P}$ dan $\mathrm{K}$ rendah sampai sedang, pori mikro banyak, tekstur lempung liat berdebu, struktur remah dan konsistensi lekat (Putinella, 2014). Pemberian bahan organik ke tanah dapat berpengaruh terhadap sifat kimia, fisik dan biologi tanah (Hardjowigeno, 2003). Pemberian pupuk dapat meningkatkan $\mathrm{pH}$ tanah, $\mathrm{P}$ tersedia tanah, serapan P dan diameter batang tanaman pada tanah Kambisol (Kaya, 2012). Sesuai pendapat Hardjowigeno (2007) pemberian bahan organik dapat meningkatkan $\mathrm{pH}$ tanah (menetralkan $\mathrm{Al}$ dengan membentuk komplek Al-organik) dan meningkatkan unsur hara mikro.

Penggunaan pupukorganik dan anorganik merupakan suatu kebutuhan bagi tanaman untuk memenuhi kebutuhan nutrisi dan menjaga keseimbangan hara yang tersediaselama siklus pertumbuhan tanaman,oleh karena itu pemberian pupuk merupakan pengelolaan yang dapat memperbaiki kesuburan tanah melalui perbaikan sifat kimia tanah (Rachman et al., 2008).Bardasarkan uraian tersebut maka perlu dilakukan penelitian untuk melihat perubahan sifat kimia tanahakibat pemberianjenis pupukdan varietas kacang tanah di tanah VertikKambisol.

\section{METODE PENELITIAN}

\section{Tempat dan Waktu}

Penelitian ini telah dilaksanakan di Muara Tiga Kabupaten Pidie dan di Laboratorium Penelitian Tanah dan Tanaman Fakultas Pertanian Universitas Syiah Kuala. Penelitian ini telah dilaksanakan mulai dari bulan Juli 2016 sampai Oktober 2016.

\section{Bahan dan Alat}

Bahan yang digunakan yaitu pupuk organik dan anorganik adalah pupuk NPK 0,117 kg plot $^{-1}$, pupuk kadang 4,68 $\mathrm{kg}_{\text {plot }}{ }^{-1}$, pupuk kompos 4,68 $\mathrm{kg} \mathrm{plot}^{-1}$ dan varietas benih kacang tanah yang digunakan dalam penelitian ini adalah varietas Tuban, HypoMa 2, Bima, Kelinci dan Gajah.Alat yang digunakan berupa cangkul, bor tanah, meteran, $\mathrm{pH}$ meter, kertas saring, tabung plastik, spectrofotometer, flamephotometer, mesin penguncang, serta peralatan di laboratorium kimia tanah dan tanaman.

\section{Rancangan Percobaan}

Rancangan percobaan yang digunakan dalam penelitian ini adalah Rancangan Acak Kelompok (RAK) pola faktorial 4 x 5 dengan 3 ulangan. Adapun faktor yang diteliti yaitu jenis 
pupuk (J) varietas kacang tanah (V).Penelitian ini terdiri dari 20 kombinasi perlakuan dengan tiga ulangan sehingga terdapat 60 satuan percobaan.

\section{PelaksanaanPenelitian}

Pengambilan contoh tanah awal dilakukan sebelum penanaman tanaman kacang tanah, dengan mengambil 3 contoh sampel tanah secara diagonal luasan lahan penelitian sehingga dapat mewakili dari lokasi tersebut, sampel tanah diambil pada top soil 1-20 $\mathrm{cm}$ dan pada sub soil 20-40 cm dengan menggunakan bor tanah setelah itu sampel tanah dianalisis di Laboratorium Penelitian Tanah dan Tanaman. Pada saat umur tanaman kacang tanah 45 HST dan 93 HST kacang tanah untuk mengetahui pengaruh dari pemberian kombinasi pupuk pada tanah Vertik Kambisol akan diambil sampel tanah dalam setiap bedeng lima sub sampel pada top soil dan lima sub sampel pada sub soil kemudian dikomposit. Hasil dari komposit dianalisis sifat kimia meliputi $\mathrm{pH} \mathrm{H}_{2} \mathrm{O}$, C-organik, N-total, P-tersedia, $\mathrm{K}$ dd, KTK.

Lahan yang digunakan pada penelitian ini adalah lahan dengan jenis tanah Vertik Kambisol didaerah Laweung, Kecamatan Muara Tiga, Kabupaten Pidie, lahan dibagi menjadi tiga kelompok (blok) dengan jarak antara kelompok (blok) $50 \mathrm{~cm}$, setiap kelompok (blok) dibagi atas 20 bedeng dengan ukuran per bedeng panjang 3,9 m lebar 1,2 $\mathrm{m}$ dan dengan jarak taman $30 \times 30 \mathrm{~cm}$.

\section{a. Pengolahan Lahan}

Pengolahan lahan untuk tanaman kacang tanah dimulai sebelum atau menjelang musim penghujan. Pada prinsipnya pengolahan tanah dilakukan untuk menciptakan kondisi yang optimal bagi pertumbuhan tanaman, yaitu menciptakan keseimbangan antara padatan, aerasi dan kelembaban tanah dengan traktor $2 x$ pengolahan. Pembuatan bedengan dilakukan dengan cara mencangkul dimana bedengan itu berukuran 3,9 m x 1,2 m.

\section{b. Pemberian Pupuk}

Pemberian pupuk kandang dan kompos dilakukan sebelum penanaman kacang tanah kemudian dibiarkan selama satu minggu. Pemberian pupuk NPK pada saat penanaman kacang tanah.

\section{c. Penanaman}

Penanamandilakukandengancaramembuatlubangtanamdenganjaraktanam $30 \mathrm{~cm}$ x30 $\mathrm{cm}$. Setelah lubang tugal terbentuk kemudian 2 butir benih dimasukkan ke dalam setiap lubang tanam dan selanjutnya ditutup kembali dengan tanah. Penanaman di lakukan sesuai perlakuan varietas pada setiap plot.

\section{d. Pemeliharaan}

Perubahan Sifat Kimia Tanah Vertik Kambisol Akibat Pemberian Jenis Pupuk dan Varietas Kacang Tanah (Arachis hypogaea L.) Di Muara Tiga Di Kabupaten Pidie (Wardia Rahmi, Teuku 
Pemeliharaan tanaman kacang meliputi penyiangan, pembumbunan, penyiraman, pengendalian organisme pengganggu tanaman(OPT) dan pengendalian gulma. Pembumbunan dilakukan disekitar tanaman berumur 15 HST dan 30 HST bersamaan penyiangan dengan menggunakan cangkul. Penyiraman dilakukan setiap sore hari, kecuali hari hujan. Pengendalian gulma dilakukan secara manual bila ada rumput atau gulma yang tumbuh.

\section{e. Pemanenan}

Pemanenan dilakukan ketika tanaman sudah berumur 100 hari setelah tanam yaitu ciriciri tanaman sudah bisa dipanen batangnya sudah keras, daunnya sudah menguning dan apabila dicabut polongnya sudah keras.

\section{Parameter Analisis Kimia Tanah}

Adapun parameter pengamatan dan analisis sifat kimia tanah dilakukan yaitu $\mathrm{pH} \mathrm{H}_{2} \mathrm{O}$, C-organik, N-total, P-tersedia, Kdd dan KTK.

\section{HASIL DAN PEMBAHASAN}

\section{Hasil Analisis}

\section{Hasil Analisis Tanah Sebelum Penelitian}

TanahVertik Kambisol yang digunakan pada penelitian ini memiliki tekstur lempung berpasir, dengan $\mathrm{pH}$ agak masam dan kandungan bahan organik yang rendah.Jenis pupuk organik yang digunakan terdiri dari pupuk kandang dan pupuk kompos. Pupuk kandang yang digunakan adalah pupuk kandang sapi yang mengandung kadar $\mathrm{N}$-total 1,31\% (sangat tinggi), kadar air 13,42\%, pH 9,40 (alkali), C-organik 28,52\% (sangat tinggi), $\mathrm{P}_{2} \mathrm{O}_{5}$ 2,69\% (sangat tinggi), dan $\mathrm{K}_{2} \mathrm{O} 6,69 \%$ (sangat tinggi), sedangkan pupuk kompos yang digunakan mengandung kadar hara $\mathrm{N}$-total 1,17\% (sangat tinggi) kadar air 15,47\%, pH 6,80 (netral).

Tabel 3. Hasil Analisis Tanah Sebelum Penelitian.

\begin{tabular}{|c|c|c|c|c|c|c|}
\hline \multirow{2}{*}{ No. } & \multirow{2}{*}{$\begin{array}{l}\text { Macam analisis dan metode } \\
\text { analisis tanah }\end{array}$} & \multirow{2}{*}{ Satuan } & \multicolumn{4}{|c|}{ Hasil analisis } \\
\hline & & & $\begin{array}{l}\text { Top } \\
\text { Soil }\end{array}$ & *Kriteria & Sub Soil & * Kriteria \\
\hline
\end{tabular}




\begin{tabular}{|c|c|c|c|c|c|c|}
\hline 1 & $\mathrm{pH}\left(\mathrm{H}_{2} \mathrm{O}\right)(1: 2.5)$ & - & 6,36 & $\begin{array}{c}\text { Agak } \\
\text { masam }\end{array}$ & 6,33 & $\begin{array}{c}\text { Agak } \\
\text { masam }\end{array}$ \\
\hline 2 & C-organik (Walkey \& Black) & $\%$ & 1,04 & Rendah & 0,63 & $\begin{array}{l}\text { Sangat } \\
\text { rendah }\end{array}$ \\
\hline 3 & N-total (Kjeldahl) & $\%$ & 0,23 & Sedang & 0,17 & Rendah \\
\hline 5 & P (Bray II) & $\mathrm{mg} \mathrm{kg}^{-1}$ & 9,77 & Rendah & 6,78 & Rendah \\
\hline 6 & $\mathrm{~K}\left(1 \mathrm{NNH}_{4} \mathrm{OAc} \mathrm{pH} 7\right)$ & cmol.kg-1 & 0,37 & Sedang & 0,30 & sedang \\
\hline 7 & $\mathrm{KTK}\left(1 \mathrm{NNH}_{4} \mathrm{OAc} \mathrm{pH} 7\right)$ & cmol.kg-1 & 42,23 & $\begin{array}{l}\text { Sangat } \\
\text { tinggi }\end{array}$ & 42,67 & $\begin{array}{c}\text { Sangat } \\
\text { tinggi }\end{array}$ \\
\hline
\end{tabular}

*Sumber: Hardjowigeno (1995)

\section{Pengaruh Perlakuan Terhadap Sifat Kimia Tanah}

\section{Pengaruh Perlakuan Terhadap pH $\mathrm{H}_{2} \mathrm{O}$ Tanah Kacang Tanah}

Berdasarkan Tabel4 hasil analisis sidik ragam/uji $\mathrm{F}$ pH $\mathrm{H}_{2} \mathrm{O}$ tanah pada umur 45 HST kacang tanah tidak berpengaruh nyata akibat penggunaan jenis pupuk dan perlakuan varietas. Tidak terdapat interaksi antara perlakuan jenis pupuk dan varietas kacang tanah terhadap $\mathrm{pH}$ $\mathrm{H}_{2} \mathrm{O}$ umur 45 HST kacang tanah. Tabel 4 dapat dilihat bahwa hasil analisis sidik ragam/uji $\mathrm{F}$ $\mathrm{pH} \mathrm{H}_{2} \mathrm{O}$ pada umur 93 HST tidak berpengaruh nyata akibat pemberian jenis pupuk dan perlakuan varietas.Tidak terdapat interaksi antara perlakuan jenis pupuk dan varietas kacang tanah terhadap $\mathrm{pH} \mathrm{H}_{2} \mathrm{O}$ pada umur 93 HST kacang tanah.Perubahan ini diduga dikarenakan setelah penambahan jenis pupuk yang telah dahulu mengalami proses dekomposisi sesuai dengan pendapat Sihite et al., (2016), $\mathrm{pH} \mathrm{H}_{2} \mathrm{O}$ tanah setelah penambahan jenis pupuk meningkat dikarenakan dekomposisi dari bahan organik akan membentuk sejumlah senyawa organik yaitu asam fulfat dan humat dapat mengkhelat ion logam dalam tanah masam. Hal ini sesuai dengan hasil penelitian Kateren (2008), pemberian pupuk dapat meningkatkan $\mathrm{pH}$ dibandingkan dengan perlakuan tanpa pemupukan.

Tabel 4. Rata-rata nilai $\mathrm{pH} \mathrm{H}_{2} \mathrm{O}$ tanah akibat penggunaan jenis pupuk dan varietas kacang tanah pada umur 45 HST dan umur 93 HST

\begin{tabular}{|c|c|c|c|c|}
\hline \multirow[b]{2}{*}{ Perlakuan } & \multirow{2}{*}{$\begin{array}{c}\text { Rerata } \\
\mathrm{pH} \mathrm{H}_{2} \mathrm{O} \text { Umur } \\
45 \mathrm{HST}\end{array}$} & \multicolumn{3}{|c|}{ Rerata } \\
\hline & & Kriteria & $\begin{array}{c}\mathrm{pH} \mathrm{H}_{2} \mathrm{O} \text { Umur } \\
93 \mathrm{HST}\end{array}$ & Kriteria \\
\hline Jenis Pupuk & & & & \\
\hline$J_{1}=$ NPK 0,117 kg plot ${ }^{-1}$ & 6,96 & Netral & 6,50 & Agak Masam \\
\hline $\mathrm{J}_{2}=\underset{1}{\text { Pupuk kandang }} 4,68 \mathrm{~kg}$ plot $^{-}$ & 7,03 & Netral & 6,56 & Agak Masam \\
\hline$J_{3}=\operatorname{Kompos} 4,68 \mathrm{~kg}$ plot $^{-1}$ & 6,93 & Netral & 6,54 & Agak Masam \\
\hline 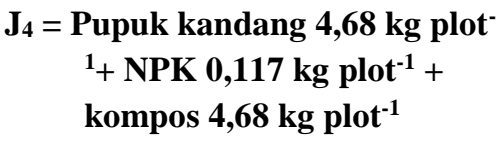 & 6,95 & Netral & 6,69 & Netral \\
\hline $\begin{array}{l}\text { Varietas Kacang Tanah } \\
V_{1}=\text { Varietas Tuban }\end{array}$ & 6,91 & Netral & 6,58 & Agak Masam \\
\hline
\end{tabular}

Perubahan Sifat Kimia Tanah Vertik Kambisol Akibat Pemberian Jenis Pupuk dan Varietas Kacang Tanah (Arachis hypogaea L.) Di Muara Tiga Di Kabupaten Pidie (Wardia Rahmi, Teuku 


\begin{tabular}{lllll}
$\mathbf{V}_{\mathbf{2}}=$ Varietas Hypoma 2 & 6,95 & Netral & 6,63 & Netral \\
$\mathbf{V}_{\mathbf{3}}=$ Varietas Bima & 7,02 & Netral & 6,65 & Netral \\
$\mathbf{V}_{\mathbf{4}}=$ Varietas Kelinci & 6,95 & Netral & 6,58 & Agak Masam \\
$\mathbf{V}_{\mathbf{5}}=$ Varietas Gajah & 7,01 & Netral & 6,42 & Agak Masam \\
\hline
\end{tabular}

\section{Pengaruh Perlakuan Terhadap C- Organik Tanah}

Berdasarkan Tabel 5 hasil analisis sidik ragam/uji F menunjukkan bahwa jenis pupuk berpengaruh nyata terhadap C-organik tanah pada tanaman kacang tanah umur 45 HST.Perlakuan varietas tidak berpengaruh nyata terhadap C-organik tanah umur 45 HST kacang tanah dan tidak terdapat interaksi antara perlakuan jenis pupuk dan varietas kacang tanah terhadapC-organik umur 45 HST kacang tanah. Tabel 5hasil analisis sidik ragam/uji $\mathrm{F}$ menunjukkan bahwa jenis pupuk tidak berpengaruh nyata terhadap C-organik tanah pada tanaman kacang tanah umur 93 HST kacang tanah dan perlakuan varietas juga tidak berpengaruh nyata terhadap C-organik tanah pada tanaman kacang tanah umur 93 HST. Tidak terdapat interaksi antara perlakuan jenis pupuk dan varietas kacang tanah terhadap C-organik tanah umur 93 HST kacang tanah.Sesuai dengan pendapat Karo et al., (2017), merupakan bahan utama organik sehingga dengan penambahan bahan organik (pupuk kandang dankompos) dapat menambah C-organik dalam tanah. Tingginya kadar C-organik tanah mempunyai sifat tanah menjadi lebih baik (Nuryani et al., 2003).

Tabel 5.Rata-rata nilai C-Organik akibat penggunaan jenis pupuk dan varietas kacang tanah pada umur 45 HST dan umur 93 HST (\%)

\begin{tabular}{|c|c|c|c|c|}
\hline \multirow[b]{2}{*}{ Perlakuan } & \multirow{2}{*}{$\begin{array}{c}\text { Rerata } \\
\text { C-Organik Umur } \\
45 \text { HST }\end{array}$} & \multicolumn{2}{|r|}{ Rerata } & \multirow[b]{2}{*}{ Kriteria } \\
\hline & & Kriteria & C-Organik Umur 93 HST & \\
\hline \multicolumn{5}{|l|}{ Jenis Pupuk } \\
\hline$J_{1}=$ NPK 0,117 kg plot ${ }^{-1}$ & $1,45 \mathrm{a}$ & Rendah & 1,27 & Rendah \\
\hline $\begin{array}{c}\mathrm{J}_{2}=\underset{\text { Plot }^{-1}}{\text { Pupuk kandang }} \\
\text { 4,68 } \mathrm{kg} \\
\end{array}$ & $1,55 \mathrm{~b}$ & Rendah & 1,33 & Rendah \\
\hline $\mathrm{J}_{3}=\operatorname{Kompos}$ 4,68 kg plot ${ }^{-1}$ & $1,63 \mathrm{c}$ & Rendah & 1,24 & Rendah \\
\hline $\begin{aligned} \mathrm{J}_{4}= & \text { Pupuk kandang 4,68 kg } \\
& \text { plot }^{-1}+\text { NPK0,117 kg } \\
& \text { plot }^{-1}+\text { kompos } 4,68 \\
& \text { kg plot }^{-1}\end{aligned}$ & $1.74 \mathrm{c}$ & Rendah & 1,36 & Rendah \\
\hline BNT 0,05 & 0,24 & & & \\
\hline \multicolumn{5}{|l|}{ Varietas Kacang Tanah } \\
\hline$V_{1}=$ Varietas Tuban & 1,60 & Rendah & 1,28 & Rendah \\
\hline$V_{2}=$ Varietas Hypoma 2 & 1,50 & Rendah & 1,30 & Rendah \\
\hline$V_{3}=$ Varietas Bima & 1,59 & Rendah & 1,31 & Rendah \\
\hline$V_{4}=$ Varietas Kelinci & 1,64 & Rendah & 1,37 & Rendah \\
\hline$V_{5}=$ Varietas Gajah & 1,64 & Rendah & 1,25 & Rendah \\
\hline
\end{tabular}

Berdasarkan hasil C-Organik meningkat setelah penambahan jenis pupuk hal ini sesuai dengan penyataan (Karo et al., 2017) yaitu karbon merupakan bahan utama organik sehingga dengan penambahan bahan organik kompos dan pupuk kandang dapat menambah C-organik 
dalam tanah. Tinggi kadar C-organik dalam tanah mempengaruhi sifat tanah menjadi lebih baik (Nuryaniet al., 2003).

Berdasarkan hasil analisis C-organik penggunaan kombinasi pupuk memberikan nilai lebih tinggi dibandingkan dengan penggunaan pupuk tunggal. Namun berdasarkan hasil analisis C-organik umur 45 HST mengalami penurunan. Penurunan diduga jenis pupuk yang diberikan terjadi perubahan senyawa organik menjadi senyawa sederhana. Hal ini sesuai dengan pernyataan Sukarwati(2011), penurunan C-organik disebabkan dengan adanya proses dekomposisi bahan organik dirombak menjadi senyawa anorganik sehingga kadar C-organik menurun.

\section{Pengaruh Perlakuan Terhadap N-total Tanah}

Berdasarkan hasil analisis sidik ragam/uji F N-total pada umur 45 HST kacang tanah tidak berpengaruh nyata akibat perlakuan jenis pupuk dan perlakuan varietas juga tidak berpengaruh nyata terhadap N-total umur 45 HST kacang tanah. Tidak terdapat interaksi antara perlakuan jenis pupuk dan varietas kacang tanah terhadap N-total pada umur 45 HST kacang tanah.Hasil analisis sidik ragam/uji $\mathrm{F}$ N-total pada umur 93 HST kacang tanah tidak berpengaruh nyata akibat pemberian jenis pupuk dan perlakuan varietas juga tidak berpengaruh nyata terhadap N-total pada umur 93 HST kacang tanah.Tidak terdapat interaksi antara perlakuan jenis pupuk dan varietas kacang tanah terhadap N-total pada umur 93 HST kacang.

Tabel 6. Rata-rata nilai N-total akibat penggunaan jenis pupuk dan varietas kacangtanah pada umur 45 HST dan umur 93 HST (\%)

\begin{tabular}{|c|c|c|c|c|}
\hline Perlakuan & $\begin{array}{c}\text { Rerata } \\
\text { N-total Umur } 45 \\
\text { HST } \\
\end{array}$ & Kriteria & $\begin{array}{c}\text { Rerata } \\
\text { N-total umur } 93 \\
\text { HST } \\
\end{array}$ & Kriteria \\
\hline \multicolumn{5}{|l|}{ Jenis Pupuk } \\
\hline $\mathrm{J}_{1}=$ NPK 0,117 kg plot $^{-1}$ & 0,22 & Sedang & 0,20 & Rendah \\
\hline $\begin{aligned} & \mathbf{J}_{2}= \text { Pupuk kandang } 4,68 \mathrm{~kg} \\
& \text { plot }^{-1}\end{aligned}$ & 0,22 & Sedang & 0,21 & Sedang \\
\hline $\begin{array}{c}\mathrm{J}_{3}=\underset{\text { plot }^{-1}}{\text { Kompos }} \text { 4,68 kg } \\
\text {. }\end{array}$ & 0,22 & Sedang & 0,20 & Rendah \\
\hline $\begin{aligned} \mathrm{J}_{4}= & \text { Pupuk Kandang 4,68 kg } \\
& \text { plot }^{-1}+\text { NPK 0,117kg plot } \\
& { }^{1} \text { kompos4,68 kg plot }^{-1}\end{aligned}$ & 0,21 & Sedang & 0,20 & Sedang \\
\hline \multicolumn{5}{|l|}{ Varietas Kacang Tanah } \\
\hline$V_{1}=$ Varietas Tuban & 0,22 & Sedang & 0,21 & Sedang \\
\hline$V_{2}=$ Varietas Hypoma 2 & 0,22 & Sedang & 0,21 & Sedang \\
\hline$V_{3}=$ Varietas Bima & 0,22 & Sedang & 0,20 & Rendah \\
\hline $\mathbf{V}_{4}=$ Varietas Kelinci & 0,22 & Sedang & 0,21 & Sedang \\
\hline$V_{5}=$ Varietas Gajah & 0,22 & Sedang & 0,21 & \\
\hline
\end{tabular}

Perubahan Sifat Kimia Tanah Vertik Kambisol Akibat Pemberian Jenis Pupuk dan Varietas Kacang Tanah (Arachis hypogaea L.) Di Muara Tiga Di Kabupaten Pidie (Wardia Rahmi, Teuku 
Berdasarkan nilai rata-rata N-total pada umur 45 HST mengalami peningkatan setelah penambahan jenis pupuk, hal ini diduga disebabkan karena jenis pupuk yang diberikan mengandung hara Nitrogen, karena bahan organik yang diberikan sudah mengalami dekomposisi terlebih dahulu. Sesuai dengan pernyataan Utami (2004), bahan organik mengandung hara Nitrogen lebih banyak dan laju proses terjadi pembebasan Nitrogen melalui proses mineral dari sisa-sisa babedengn organik yang dibutuhkan mikroorganisme. Penambahan jenis pupuk meningkatkan N-total tanah meskipun peningkatan tidak besar, peningkatan N-total dari mineralisasi bahan organik yang diberikan (Afandi et al., 2015).

\section{KESIMPULAN}

Pemberian jenis pupuk berpengaruh nyata terhadap C-organik umur 45 HST kacang tanah, namun tidak berpengaruh nyata terhadap $\mathrm{pH} \mathrm{H}_{2} \mathrm{O}$ tanah umur 45 HST dan 93 HST kacang tanah, C-organik umur 93 HST kacang tanah, N-total pada umur 45 HST dan 93 HST kacang tanah, P umur 93 HST kacang tanah, dan KTK pada umur 93 HST kacang tanah. Pengunaan varietas tidak berpengaruh nyata terhadap $\mathrm{pH} \mathrm{H}_{2} \mathrm{O}, \mathrm{C}$-organik, , N-total, pada umur 45 HST dan pada umur 93 HST kacang tanah.Tidak terdapat interaksi antara perlakuan jenis pupuk dan varietas kacang tanah terhadap $\mathrm{pH} \mathrm{H}_{2} \mathrm{O}$, C-organik, $\mathrm{N}$-total, pada umur 45 HST dan juga pada umur 93 HST kacang tanah.

\section{DAFTAR PUSTAKA}

Abdurachman, A., A. Dariah dan A. Mulyani. 2008. Strategi dan teknologi pengelolaan lahan kering mendukung pengadaan pangan nasional. Jurnal Litbang Pertanian V 27:2.

Afandi, F.N., B. Siswanto dan Y. Nuraini, 2015. Pengaruh Pemberian Berbagai Bahan Organik Terhadap Sifat Kimia pada Pertumbuhan dan Produksi Tanaman Ubi Jalar di Entisol Ngangkah Pawon Kediri. Jurnal Tanah dan Sumber Daya Lahan. V 2:2.

Akhtar, M.E., K. Bashir, M.Z. Khan, dan K.M. Khokhar. 2003. Effect of Potash Application on Yield of Different Varieties of Onion (Allium cepa L.). Asian Journal of Plant Sciences. V 1:4.

Alibasyah, M.R. 2016. Perubahan Beberapa Sifat Fisika \& Kimia Ultisol Akibat Pemberian Pupuk Kompos \& Kapur Dolomit Pada Lahan Berteras. Jurnal Foratek V 11:1..

Frobel, G.D., J.J.M.R. Londok, R.A.V. Tuturoong dan W.B. Kaunang. 2013. Pengaruh Pemupukan Anorganik dan Organik terhadap Produksi Tanaman Jagung sebagai Sumber Pakan. Jurnal Zootek. V 32:5.

Gomez, K.A. dan A.A. Gomez 1995. Prosedur Statistik Untuk Penelitian Pertanian, Alih Bahasa: E. Syamsuddin\& J. S. Baharsya, Universitas Indonesia, Jakarta.

Hardjowigeno, S.1995. Ilmu Tanah. Akademika Pressindo. Jakarta.

Hardjowigeno, S. 2007. Ilmu Tanah. Akademika Pressindo. Jakarta. 
Hasibuan, B. E. 2006. Pupuk dan Pemupukan. USU-Press.Medan.

Irawan, A., Y. Jufri dan Zuraida, 2016. Pengaruh Pemberian Bahan Organik Terhadap Perubahan Kimia Andisol Pertumbuhan dan Produksi Gandum (Triticum Eastivum L). Jurnal Kawista. V 1:1

Karo, A.K., A. Lubis dan Fauzi. 2017. Perubahan Beberapa Sifat kimia Tanah Ultisol Akibat Pemberian Beberapa Pupuk Organik \& Waktu Inkubasi. Jurnal Agroekoteknologi FP USU. V 5:2

Kaya, E. 2012. Pengaruh Pemberian Kompos Ela Sagu dan Pupuk ABG Bunga-Buah Terhadap P-Tersedia, Serapan-P, Serta Pertumbuhan Tanaman Jagung (Zea Mays L.) Pada Inceptisol. Jurnal Buana Sains, V 12:1.

Ketaren, J.N. 2008. Perubahan Beberapa Sifat Kimia Tanah Andisol pada Sistem Pertanian Organik Akibat Pengolahan Tanah \& Pemberian Pupuk Organik. Departemen Ilmu Tanah Fakultas Pertanian Universitas Sumatra Utara. Medan.

Nuryani, S., H. Utami dan S. Handayani. 2003. Sifat Kimia Entisol pada Sistem Pertanian Organik. Jurnal Ilmu Pertanian .Vol 10:2.

Purnawati, I. 2013. Analisis Rawan Kekeringan Lahan Pertanian Tanaman Pangan dengan Memanfaatkan Citra Quickbird dan Sistem Informasi Geografis Kabupaten Bantul. Fakultas Geografi Universitas Muhammadiyah. Surakarta.

Putinella, A.P. 2014. Perbaikan Fisik Tanah Kambisol Akibat Pemberian Bokashi Ela Sagu Dan Pupuk ABG (Amazing Bio Growth) Bunga-Buah. Jurnal Budidaya Pertanian, V $10: 1$.

Rachman, I.A., S. Djuniwati dan K. Indris, 2008. Perubahan Bahan Organik dan Pupuk NPK Terhadap Serapan Hara dan Produksi Jagung Di Inceptisol Ternate. Jurnal Tanah dan Lingkungan. V:10:1.

Samadi, B. dan C. Bambang. 2005. Bawang Merah, Intensifikasi dan Budidaya. Penerbit Kanisius. Yogyakarta.

Sihite, E.A., U.M.B Damanik, M. Sembiring 2016. Perubahan Beberapa Sifat Kimia Tanah, Serapa P dan Pertumbuhan Tanaman Jagung pada Tanah Inceptisol kwala Bekala Akibat Perberian Pupuk Kandang Ayam \& beberapa Sumber P. Jurnal Agroekoteknologi Vol $4: 3$.

Singh, S. P. and Verma, A. B. 2001. Response of Onion (Allium cepa) to Potassium Application. Indian Journal of Agronomy. V 46.

Soepardi, G. 1983. Sifat Dan Ciri Tanah. Jurusan Tanah. Fakultas Pertanian IPB. Bogor. 
Sukarwati, S. 2011. Jerapan P Pada Tanah Andisol yang Berkembang dari Tuff Vulkam Gunung Api di Jawa Tengah dengan Pemberian Asam Humat \& Asam Sililikat. Media Limbang Sunteng.

Tufaila, M. dan S. Alam. 2014. Karakteristik Tanah dan Evaluasi Lahan Untuk Pengembangan Tanaman Padi Sawah Dikecamatan Oheo Kabupaten Kanowe Utara. Jurnal Agriplus. V.24.

Utami, S.M.H. 2004. Sifat Kimia Andisol pada Pertanian Organik. Jurnal Insitut Pertanian Bogor.. 